\title{
ASSESSMENT OF THE ATMOSPHERIC IMPACT OF VOLCANIC ERUPTIONS
} H. Sigurdsson, Graduate School of Oceanography, University of Rhode Island, Kingston, R.I. 02881

The dominant global impact of volcanic activity is likely to be related to the effects of volcanic gases on the Earth's atmosphere. Two types of volcanic impact can be considered: a) the well-known climatological impact caused by increase in the aerosol optical thickness of the stratosphere due to injection of sulfur compounds, leading to tropospheric cooling and b) the more speculative effects of volcanic chlorine, other halogens and $\mathrm{OH}$ radicals from dissociation of magmatic water on the Earth's stratospheric ozone layer. Two factors indicate that erupted silicate particles, i.e. volcanic ash, do not play an important role as agents of atmospheric impact. Firstly, Pollack et al. (1976) have shown that the optical properties of volcanic ash are distinct from those of volcanic aerosols such as sulfuric acid. Secondly, the atmopsheric residence time of even the finest grained volcanic ash is relatively short due to the process of particle aggregation and premature fallout (Carey and Sigurdsson, 1982). The yield to the atmosphere (mass fraction of volatile component emitted) of sulfur, halogens and magmatic water varies greatly with magma composition (Sigurdsson, 1982; Devine et al. 1984; Palais and Sigurdsson, 1988). Because of these effects, it is apparent that the potential climatic impact of a volcanic eruption is not primarily governed by the degree of explosivity or the volume of erupted magma, but more importantly by the chemical composition of the magma. Thus the climatological effects of volcanic aerosol emission from large basaltic fissure eruptions may in fact be more important than the effects of explosive eruptions of silicic magmas of comparable magnitude. Finally, atmospheric impact is dependent on the rate of volcanic volatile input, as the stratospheric half-life of a large volcanic aerosol such as from the 1815 Tambora eruption is only of the order of two years (Stothers, 1984).

Source rates of volcanic volatiles in past eruptions can be determined by petrologic studies of glass inclusions in phenocrysts in tephra. Results show that the average atmospheric yield of sulfur from basaltic, intermediate and silicic eruptions is 600,560 and $70 \mathrm{ppm}$, respectively; 65,920 and $135 \mathrm{ppm}$ for chlorine and 100,500 and $160 \mathrm{ppm}$ for fluorine (Palais and Sigurdsson, 1988). These ressults indicate that even the large rhyolite and dacite caldera-forming ignimbrite eruptions of Yellowstone, Toba, Long Valley etc. are unlikely to have sulfur output greater than some historic eruptions of basaltic and trachytic magmas. A growing petrologic data base of volcanic volatile output from Recent and late Quaternary eruptions reveals that sulfur yield in individual events may reach $10^{10}$ to $10^{11} \mathrm{~kg}$, such as in the Laki 1783 basaltic fissure eruption in Iceland and the 1815 explosive trachytic eruption of Tambora in Indonesia. Data on sulfur output for several historic eruptions shows a good correlation $(r=0.87)$ with the observed mean decrease in Northern Hemisphere surface temperature associated with the eruption, where the mean surface temperature decrease is related to the sulfur yield by a power function, with sulfur mass raised to 0.308 (Devine et al. 1984; Palais and Sigurdsson, 1988).

Studies of Tambora 1815 and other eruptions indicates that degassing of chlorine may exceed sulfur output in certain cases. In the case of Tambora the yield of chlorine is estimated as $6.2 \times 10^{10}$ $\mathrm{kg}$, or about two orders of magnitude higher than the current annual release of chlorofluorocarbons. The same eruption emitted $4.3 \times 10^{10} \mathrm{~kg}$ fluorine, judging from petrologic evidence. Although $\mathrm{HCl}$ and $\mathrm{HF}$ gases are not known to form aerosols in the atmosphere, and are generally believed to fall out rapidly as adsorbed components on tephra, it must be stressed that the consequences on atmospheric chemistry of such large halogen injections have never been studied. Although $\mathrm{HCl}$ is inert toward ozone, reactions of $\mathrm{HCl}$ with $\mathrm{OH}$ radicals can lead to formation of atomic chlorine, followed by the catalytic decomposition of ozone. Thus chlorine output from the Tambora eruption is an order of magnitude higher than the amount required to induce a $7 \%$ ozone depletion (Stolarski and Butler, 1978). A major ozone depletion from the combined effects of volcanic halogens and magmatic water during Tambora-size eruptions must be considered.

Although mid-ocean ridge volcanism is volumetrically dominant on the Earth, the vast 
proportion of volcanic volatiles is released to the atmosphere from volcanic arcs and hotspots. This pattern may hold for much of geologic time, in the absence of evidence of the mid-ocean ridge system having been subaerial at any time in the history of the Earth after the Archean. Holocene magma production rates in volcanic arcs are estimated from 1 to $5 \times 10^{12} \mathrm{~kg} / \mathrm{yr}$ (Sample and Karig, 1982); and hotspot rate estimates range from 4 to $5 \times 10^{12} \mathrm{~kg} / \mathrm{yr}$ (Crisp, 1984). Long-term variations in hotspot rates are likely to be large, judging from the two-orders-of-magnitude range exhibited by the Hawaiian hotspot in the past $70 \mathrm{Ma}$ (Shaw, 1985). The huge but short-term output of basalts from the West Pacific hotspots in the mid-Cretaceous and the Deccan basalts at the K/T boundary dramatically illustrates the ephemeral nature of some hotspots and the problems of generalizing their volcanic volatile source rates. Long-term variations in explosive volcanism of volcanic arcs have been inferred from variations in the frequency of volcanic ash layers in deep-sea sediments, leading to the concept of global volcanic episodicity, with the most recent maxima in the Quaternary and the middle Miocene (Kennett and Thunell, 1975). More recent work indicates that the observed variations in deposition rate of deep-sea volcanic ash layers may not be a source function, but rather a reflection of transport processes, i.e. the vigor of atmospheric circulation. Variation in aeolian dust accumulation in deep-sea sediments is an index of changes in atmospheric circulation patterns and their intensity. Studies of aeolian quartz deposition rates during the Cenozoic show variations that mirror the volcanic ash layer frequency (Leinen and Heath, 1981; Rea et al. 1985). It appears therefore that we have no reliable index of variation in volcanic arc production rate with time.

In conclusion, volcanic gas emissions from individual volcanic arc eruptions are likely to cause increases in the stratospheric optical depth that result in surface landmass temperature decline of 1 to $3^{\circ} \mathrm{K}$ for less than a decade. Trachytic and intermediate magmas are much more effective in this regard than high-silica magmas, and may also lead to extensive ozone depletion due to effect of halogens and magmatic water. Given the assumed relationship between arc volcanism and subduction rate, and the relatively small variation in global spreading rates in the geologic record, it is unlikely that the rates of arc volcanism have varied greatly during the Cenozoic. Hotspot related basaltic fissure eruptions in the subaerial environment have a higher mass yield of sulfur, but lofting of the volcanic aerosol to levels above the tropopause is required for a climate impact. High-latitude events, such as the Laki 1783 eruption can easily penetrate the tropopause and enter the stratosphere, but formation of a stratospheric volcanic aerosol form low-latitude effusive basaltic eruptions is problematical, due to the elevated low-latitude tropopause. Due to the high sulfur content of hotspot-derived basaltic magmas, their very high mass eruption rates and the episodic behaviour, hotspots must be regarded as potentially major modifiers of Earth's climate through the action of their volcanic volatiles on the chemistry and physics of the atmosphere.

Carey, S.N., and H. Sigurdsson (1982) J. Geophys. Res. 87, 7061-7072.

Crisp, J.A. (1984) J. Volcanol. Geotherm. Res. 20, 177-211.

Devine, J., Sigurdsson, H., Davis, A. and Self, S. (1984) J. Geophys. Res. 89, 6309-6325.

Kennett, J.P. and R.C. Thunell (1975) Science, 187, 497-503.

Palais, J.M., and H. Sigurdsson (1988). AGU Geophysical Monograph (in press).

Pollack, J.B., O.B. Toon, C. Sagan, A. Summers, B. Baldwin and W.Van Camp, (1976) J. Geophys. Res. 81, 1071-1083.

Shaw, H.R. (1985) J. Geophys. Res. 90, 11275-11288.

Sigurdsson, H. (1982) EOS, 63, 601-602.

Sigurdsson, H., J.D. Devine and A.N. Davis (1985) Jokull, 35, 1-8.

Stolarski, R.S. and D.M. Butler (1978) Pageoph, 117, 486-497.

Stothers, R. (1984) Science, 224, 1191-1198. 